Original article

Reprint

\title{
Using endoscopic hemithyroidectomy in patients with benign thyroid diseases
}

\author{
Sergey V. Vertyankin ${ }^{1}$, Isabella A. Turlykova ${ }^{1}$, Vitaly L. Meshcheryakov ${ }^{1}$, Vladimir V. Grekov' ${ }^{1}$,

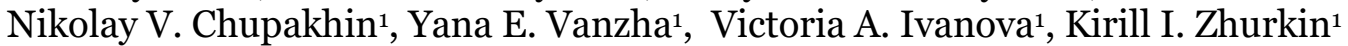

${ }^{1}$ Saratov State Medical University, Saratov, Russia

Received 28 February 2019, Accepted 20 November 2020

Original Text (c) Vertyankin S.V., Turlykova I.A., Meshcheryakov V.L., Grekov V.V., Chupakhin N.V., Vanzha Ya.E., Ivanova V.A., Zhurkin K.I., 2019, published in Saratov Journal of Medical Scientific Research 2019; 15 (2): 290-295.

(C) 2020, Vertyankin S.V., Turlykova I.A., Meshcheryakov V.L., Grekov V.V., Chupakhin N.V., Vanzha Ya.E., Ivanova V.A.,

Zhurkin K.I,

(C) 2020, Saratov Medical Journal

\begin{abstract}
:
Objective: the development and assessment of endoscopic hemithyroidectomy technique improving visualization of anatomical structures and excluding the so-called conflict of instruments in the operative field.

Materials and methods. We analyzed the treatment results of 103 patients who underwent hemithyroidectomy with endoscopic or traditional approaches during 2014-2018 at the S.R. Mirotvortsev Hospital of Saratov State Medical University. In terms of approach mode, patients were divided into two groups. The compression syndrome, functional autonomy of a thyroid, and results of a punch biopsy were indications to operation.

Results. Unilateral vocal cord paralysis (UVCP) was diagnosed in one patient after traditional intervention, diminishing after 1.5 months; and in three patients after endoscopic hemithyroidectomy, diminishing anywhere between 7 days and 1.5 months. Signs of hypoparathyroidism were not found in any of the patient groups. There were no complications associated with the introduction of carbon dioxide. No conversion was required in any of the cases.

Conclusion. Development, application and assessment of a new endoscopic hemithyroidectomy technique, which proved itself feasible, safe and provisioning highly esthetic outcome were conducted.
\end{abstract}

Keywords: thyroid, endocrine surgery, endoscopic surgery, endoscopic operations.

Cite as Vertyankin SV, Turlykova IA, Meshcheryakov VL, Grekov VV, Chupakhin NV, Vanzha YaE, Ivanova VA, Zhurkin KI. Using endoscopic hemithyroidectomy in patients with benign thyroid diseases. Saratov Medical Journal 2020; 1(2): e0205

Correspondence to Isabella A. Turlykova. Tel.: +7 (927) 221 9888; E-mail: romabella@bk.ru

\section{Introduction}

Currently, thyroid surgery follows the principles of small incisions and endoscopic approaches. This is explained by the desire to improve the quality of life and accelerate the rehabilitation of patients, since endoscopic interventions in thyroid pathology can achieve a high degree of functional and aesthetic results $[1,2]$. Since the publication of information about the first performed endoscopic interventions on the thyroid and parathyroid glands, numerous variants of such operations have become known from different approaches, including extracervical (axillary, transthoracic, transoral, posterior auricular and combined) [3-9]. These types of surgical interventions, undoubtedly, have a number of advantages over traditional approaches. For example, among the general advantages of axillary and axillary-mammary approaches, compared with traditional operations, there is an improvement in visualization of vulnerable structures, such as recurrent laryngeal nerve (RLN) and parathyroid glands (PTG), which reduces the likelihood of their damage during surgery [10]. In our opinion, the main disadvantage of currently existing gas access to the thyroid and parathyroid glands is insufficient visualization of anatomical structures due to a small volume of the operative cavity caused by low gas pressure.
Objective: to develop and evaluate a method for threetrocar endoscopic gas extracervical hemithyroidectomy from axillary and transthoracic approaches, which provides a better view of the operative field, improves visualization of anatomical structures and eliminates the so-called conflict of instruments.

\section{Materials and methods}

The results of surgical treatment of 103 patients with benign thyroid diseases, who underwent hemithyroidectomy in the period from 2014 to 2018 at the S.R. Mirotvortsev Clinical Hospital. Patients were split among two groups: 50 patients underwent three-trocar endoscopic gas extracervical hemithyroidectomy from axillary and thoracic approaches (patent application RF No. 2018118913 'Method for Endoscopic Hemithyroidectomy'); while 53 patients underwent hemithyroidectomy from the traditional approach.

Before surgery, all patients were examined in accordance with the clinical guidelines of the Russian Endocrinology Association on diagnosing and treatment of (multi) nodular goiter in adults [11]. The indications for surgical treatment for both groups of patients were: compression syndrome, 
functional autonomy of the thyroid, and punch biopsy data (category 4 of the Bethesda System) as the key method for differential diagnostic of nodular goiter [12]. However, the decision on the need for surgical intervention in the presence of compression syndrome was made regardless of the data of fine-needle aspiration biopsy (FNAB) and scintigraphy. Likewise, indications for surgery were designated from puncture data (category 4 of the Bethesda System) and in the presence of hot nodes during scintigraphy.

To perform an endoscopic operation, a standard set of laparoscopic instruments is required: (1) an anterolateral vision endoscope $30^{\circ}$, large format, $10 \mathrm{~mm}$ in diameter, 31 cm long; (2) Veress needle (for pneumoperitoneum) with a springy blunt stylet, $2.1 \mathrm{~mm}$ in diameter, $13 \mathrm{~cm}$ long; (3) two trocars with stylet, $11 \mathrm{~mm}$ in diameter, $10.5 \mathrm{~cm}$ long; (4) a trocar with a stylet, $6 \mathrm{~mm}$ in diameter, $10 \mathrm{~cm}$ long; (5) two palpation probes $35 \mathrm{~cm}$ long, $5 \mathrm{~mm}$ and $10 \mathrm{~mm}$ in diameter; (6) instruments for grasping and dissecting tissues with a diameter of $5 \mathrm{~mm}$, a length of $36 \mathrm{~mm}$; (7) suction device; and (8) container for extracting the tissue sample. In addition, an electrosurgical unit is used, which provides dosed bipolar coagulation, depending on the properties of the tissue; an attachment for bipolar coagulation and dissection, $5 \mathrm{~mm}$ in diameter and $35 \mathrm{~cm}$ in length, or a device for ultrasonic coagulation and dissection with a small damaging effect and a pronounced hemostatic effect.

Surgical intervention is performed under general anesthesia with constant intraoperative monitoring of hemodynamics, inspiratory and expiratory gas composition and blood gas composition. Hair should be removed from the neck, axillary region, up to the upper abdomen, especially in men.

The patient lies on his back with a roll under the shoulder blades to extend the neck. The arm on the affected side extends $90-120^{\circ}$ and is securely fixed. The neck, chest and arm from the ipsilateral side are treated with an antiseptic solution.

The surgeon works from the pathological focus in relation to the patient; the assistant is next to the surgeon, closer to the head end. The endoscopic complex is located at the cranial end from the contralateral side.

After the treatment of the operative field, the clavicle, the sternocleidomastoid muscle, the midline of the neck and the boundary of the thyroid gland are marked with a skin marker (Figure 1).

The incision sites are marked: the first $10 \mathrm{~mm}$ mark is applied at the projection of the pectoralis major muscle (crest of the greater tubercle on the humerus), the next $5 \mathrm{~mm}$ mark is along the upper edge of the periareolar region on the ipsilateral breast in women; in men, an incision can be made at any point in the periareolar region providing better visualization (Figure 2).

Usually the operative angle, i.e. the angle between the tools entered at points 1 and 2 is $52 \pm 5^{\circ}$. By abducting the mammary gland medially in women, it is possible to increase the angle by an average of $5-10^{\circ}$, thereby increasing it to $64 \pm 3^{\circ}$. For the same purpose, in men, a periareolar incision is made along the medial semicircle of the nipple. In this case, it is possible to increase the operating angle by $3-5^{\circ}$. The third mark is variable, it is applied along the outer edge of the pectoralis major muscle in such way that the instrument inserted in this area creates a bisector of the angle between the other two (Figure 3).
Next, the installation of instruments is carried out. The first $10 \mathrm{~mm}$ incision is made parallel to the outer edge of the pectoralis major muscle at the third point marked with a marker. Through it, carbon dioxide is injected under the subcutaneous fascia, using a Veress needle at a pressure of 18 $\mathrm{mmHg}$ when the needle is directed to the affected lobe. After the Veress needle is removed, a trocar with a stylet is inserted into its place. After the insertion of the trocar along the entire length of the stylet, the endoscope is inserted towards the lobe of the thyroid to form the primary cavity. This term means a space with dimensions of about $5.0 \times 5.0 \times 3.5 \mathrm{~cm}$, located above the clavicle and behind the lateral edge of the sternocleidomastoid muscle, created to improve the conditions for inserting instrumental trocars (Figure 4).

The primary cavity is formed by manipulating the endoscope tube with simultaneous palpation of the sternocleidomastoid muscle and carbon dioxide insufflation. The formation of this cavity allows the safe introduction of instrumental trocars, since the possibility of damage to large vessels and the occurrence of bleeding is excluded.

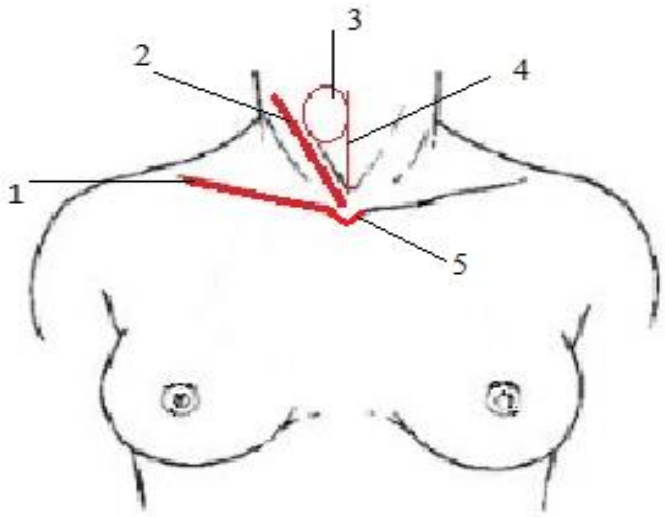

Figure 1. Marking musculoskeletal landmarks

1 - clavicle; 2 - sternocleidomastoid muscle; 3 - boundaries of the thyroid gland lobe; 4 - midline of the neck; 5 - suprasternal notch.

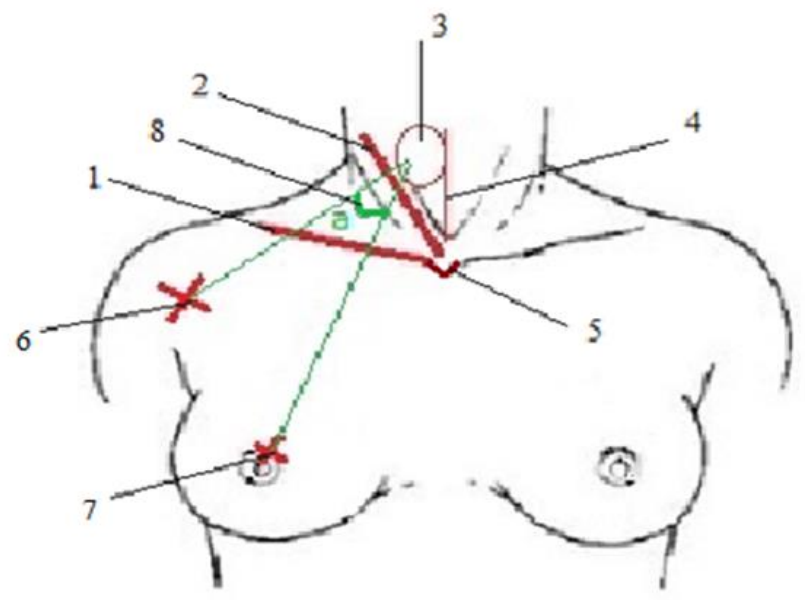

Figure 2. Determining the sites of skin incisions

1 - clavicle; 2 - sternocleidomastoid muscle; 3 - boundaries of the thyroid gland lobe; 4 - midline of the neck; 5 - suprasternal notch; 6 - the first mark is in the region of the greater tubercle on the humerus; 7 - the second mark is in periareolar region; 8 - operative angle. 


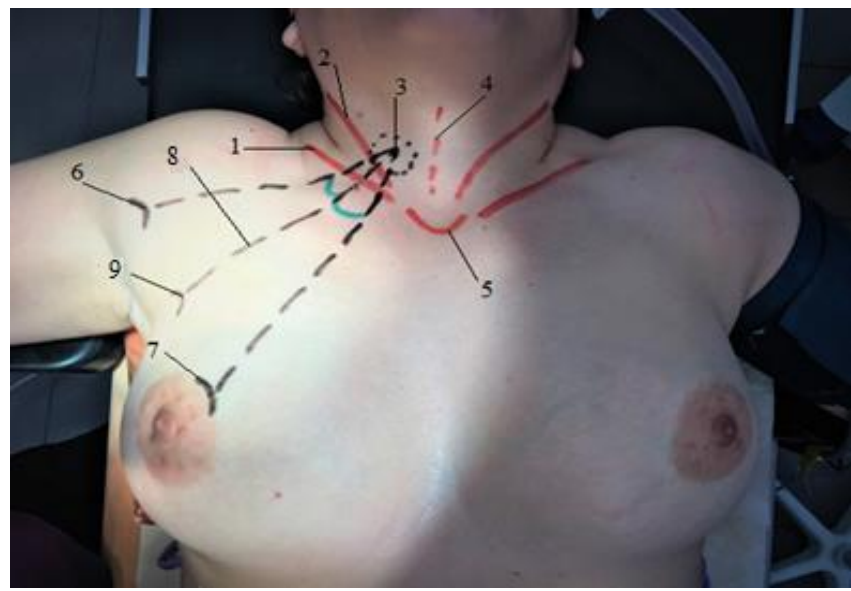

Figure 3. Determining the location of the third access point 1 - clavicle; 2 - sternocleidomastoid muscle; 3 - boundaries of the thyroid gland lobe; 4 - midline of the neck; 5 - suprasternal notch; 6 - the first mark is in the region of the greater tubercle on the humerus; 7 - the second mark is in periareolar region; 8 - operative angle bisector; 9 - the third mark.

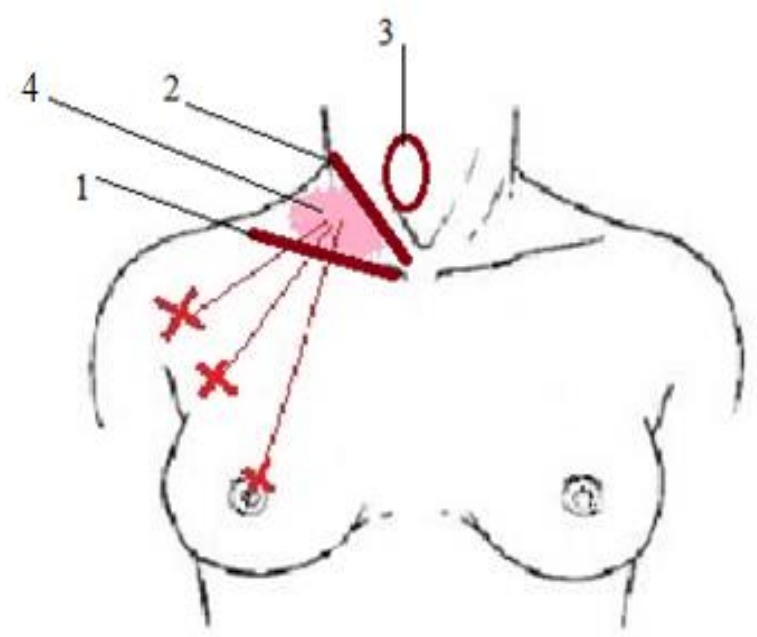

Figure 4. Borders of the primary cavity

1 - clavicle; 2 - sternocleidomastoid muscle; 3 - boundaries of the affected thyroid lobe; 4 - primary cavity.

Next, a $10 \mathrm{~mm}$ incision is made at the site of attachment of the pectoralis major muscle; a tunnel is created when a 10 $\mathrm{mm}$ trocar with a stylet is advanced inward towards the primary cavity, which is visible due to illumination with an endoscope inserted into it. After insertion of the trocar to its full length, the stylet is removed. A palpation probe with a diameter of $10 \mathrm{~mm}$ is introduced, through the manipulation of which and under the control of an endoscope, the probe is inserted into the primary cavity. After removing the palpation probe, an instrument (dissection and grasping forceps) is inserted into the trocar.

The third incision $(5 \mathrm{~mm}$ ) is made along the edge of the areola. After the incision, a subcutaneous tunnel is created by inserting a $5 \mathrm{~mm}$ trocar with a stylet towards the primary cavity. Then the stylet is removed, and a $5 \mathrm{~mm}$ diameter probe is inserted until the primary cavity is reached. After removing the palpation probe, one of the instruments for coagulation and dissection (monopolar electrocautery hook, bipolar coagulator-dissector, or harmonic scalpel) is inserted into the primary cavity.

In the course of our study, technical difficulties arose with formation of a subcutaneous tunnel of sufficient length, especially in patients with a hypersthenic constitution. Therefore, we proposed the use of trocars of greater length $25 \mathrm{~cm}$, allowing to reach the operative cavity from any point, thus limiting the diameter of the subcutaneous tunnel, reducing the risk of injury to the subcutaneous vessels, and lowering the probability of hematomas formation and extensive subcutaneous emphysema [13].

As soon as all three trocars are inserted, and the instruments 'meet' in the primary cavity, the creation of the operating cavity begins. The lateral the boundaries of the space are as follows: the lateral one is the sternocleidomastoid muscle, the upper one is the hyoid bone, the medial one is the midline of the neck, and the lower one is represented by the suprasternal notch and the sternal end of the clavicle. Dissection is performed, using one of coagulation and dissection instruments along with a soft clamp. Thus, an operative cavity of sufficient volume is created.

The sternocleidomastoid muscle is retracted downward and laterally, creating a space between itself and the infrahyoid muscles. Further, the infrahyoid muscles are abducted along the midline, and they are retracted downward and laterally, exposing the visceral surface of the thyroid.

After the muscles are separated from the visceral surface of the thyroid, the middle thyroid vein must be visualized and transected with one of the coagulation instruments. Further, the dissection continues close to the thyroid, the vessels of the lower pole are transected using a bipolar coagulatordissector or a harmonic scalpel.

After transecting the vessels of the lower pole of the thyroid, the instruments are moved upward under the control of the endoscope to mobilize the upper pole. The upper pole vessels are transected with one of coagulation and dissection instruments, as close to the thyroid tissue as possible, to preserve the outer branch of the superior laryngeal nerve.

The thyroid is then lifted upward and medially to visualize the recurrent laryngeal nerve, and superior and inferior parathyroid glands. An important issue to consider during this dissection is to avoid damage to the recurrent laryngeal nerve and parathyroid glands. Otherwise, it could lead to the development of complications in the postoperative period, especially with an enlarged Zuckerkandl tubercle. Endoscopic zoom facilitates this stage of the surgery.

After transecting large vessels, small vessels are also cut with a bipolar coagulator-dissector or an ultrasonic scalpel. Then the parathyroid gland is visualized, the Berry's ligament is transected near the trachea, along with several small junctions. After visualization of the trachea anterior surface, the mobilized thyroid lobe is retracted downward and laterally, and the isthmus is isolated and transected.

The removed thyroid lobe is placed in a bag for extracting the specimen, after which the endoscope is moved into a 10 $\mathrm{mm}$ trocar located in the area of attachment of the pectoralis major muscle. The specimen is removed through an incision located in the middle. Sometimes, with a large diameter of the removed specimen, the skin incision at the third point expands to the required size. Hemostasis is provided. All 
incisions are sutured. Drainage for this type of surgery is not performed.

In the postoperative period, the skin sutures are treated daily with an antiseptic solution (alcohol, brilliant green). The stitches are removed on the 7 th day.

Statistical data processing was conducted using Microsoft Excel 2000 and Statistica 6.0 programs. Absolute and relative indicators (\%) were calculated; for a number of parameters, their means and errors of the mean were computed. Thus, sample means are presented as $\mathrm{M} \pm \mathrm{m}$.

\section{Results}

Clinical traits of patients, indications for surgery, and distribution by nosology, based on postoperative histological examination, in two groups of patients are shown in Tables $1-3$.

Table 1. Patient traits (two groups)

\begin{tabular}{|l|c|c|c|}
\hline \multicolumn{2}{|c|}{ Trait } & $\begin{array}{c}\text { Endoscopic surgery } \\
(\mathrm{n}=50)\end{array}$ & $\begin{array}{c}\text { Open surgery } \\
(\mathrm{n}=53)\end{array}$ \\
\hline \multirow{2}{*}{ Gender } & female $(\%)$ & $44(88.0)$ & $39(73.6)$ \\
\cline { 2 - 4 } & male (\%) & $6(12.0)$ & $14(26.4)$ \\
\hline Age, years $(\mathrm{M} \pm \mathrm{m})$ & $35.7 \pm 3.3$ & $48.7 \pm 3.4$ \\
\hline $\begin{array}{l}\text { Thyroid lobe volume, } \mathrm{cm}^{3} \\
(\mathrm{M} \pm \mathrm{m})\end{array}$ & $15.9 \pm 2.6$ & $17.0 \pm 3.3$ \\
\hline $\begin{array}{l}\text { Surgery duration, min } \\
(\mathrm{M} \pm \mathrm{m})\end{array}$ & $57.1 \pm 6.7$ & $54.7 \pm 4.1$ \\
\hline
\end{tabular}

Table 2. Indications for surgery in two groups of patients

\begin{tabular}{|c|c|c|}
\hline Indication for surgery & $\begin{array}{c}\text { Endoscopic surgery } \\
(\mathrm{n}=50)\end{array}$ & $\begin{array}{c}\text { Open surgery } \\
(\mathrm{n}=53)\end{array}$ \\
\hline $\begin{array}{c}\text { Compression } \\
\text { syndrome without FNAB } \\
\text { and scintigraphy data }\end{array}$ & $32(64.0 \%)$ & $33(62.2 \%)$ \\
\hline $\begin{array}{c}\text { Punch biopsy data } \\
\text { (Bethesda 4-5) }\end{array}$ & $12(24.0 \%)$ & $11(20.8 \%)$ \\
\hline $\begin{array}{c}\text { Functional thyroid } \\
\text { autonomy based on } \\
\text { scintigraphy data }\end{array}$ & $6(12.0 \%)$ & $9(17.0 \%)$ \\
\hline
\end{tabular}

FNAB - fine-needle aspiration biopsy.

Table 3. Distribution of patients by nosology based on postoperative histological examination

\begin{tabular}{|l|c|c|}
\hline Nosology & $\begin{array}{c}\text { Endoscopic surgery } \\
(\mathrm{n}=50)\end{array}$ & $\begin{array}{c}\text { Open surgery } \\
(\mathrm{n}=53)\end{array}$ \\
\hline Nodular goiter & $24(48.0 \%)$ & $19(35.8 \%)$ \\
\hline Multinodular goiter & $11(22.0 \%)$ & $17(32.1 \%)$ \\
\hline Follicular adenoma & $9(18.0 \%)$ & $8(15.1 \%)$ \\
\hline Toxic adenoma & $6(12.0 \%)$ & $9(17.0 \%)$ \\
\hline
\end{tabular}

(C) 2020, Saratov State Medical University, Saratov, Russia
The average age of patients in the group of endoscopic interventions was 35 years old, while in the group of traditional surgery it was 48 years old. Most patients in both groups were women. Compression syndrome became the most common indication for surgery.

The average operation time under endoscopic approach was slightly higher than with the intervention, using traditional approach ( $57.1 \mathrm{~min}$ vs. $54.7 \mathrm{~min}$ ). The volume of removed thyroid lobe, on average, was $15.7 \mathrm{~cm} 3$ in the first group and $17.0 \mathrm{~cm} 3$ in the second group.

In the group of patients who underwent hemithyroidectomy with traditional approach, one patient was diagnosed with unilateral paresis of laryngeal muscles, which was regarded tractional and completely diminished after 1.5 months. There were no signs of hypoparathyroidism in this group of patients.

In the postoperative period, in three patients $(6 \%)$, who underwent three-trocar endoscopic gas extracervical hemithyroidectomy from the axillary and transthoracic approaches, unilateral paresis of laryngeal muscles was diagnosed, which completely diminished in one case after 7 days, in the second case within 3 weeks, and in the third case after 1.5 months. It should be noted that these complications in patients were recorded at the stage of mastering a new surgical technique.

Hypoparathyroidism was not diagnosed in any of the patients in this group. There were no complications associated with the introduction of carbon dioxide. Postoperative emphysema resolved completely within 24-48 hours. Conversion was not required in any of 50 cases of endoscopic intervention. There were no difficulties with retrieving the removed specimen in any of the cases. There were no other complications in this group of patients.

Contemporary anesthetic management prevents the development of negative consequences of high pressure and makes it safe to perform a three-trocar endoscopic gas extracervical hemithyroidectomy from the axillary and thoracic approaches.

\section{Discussion}

After analyzing the surgical treatment results in patients with benign thyroid diseases, who underwent three-trocar endoscopic gas extracervical hemithyroidectomy from the axillary and thoracic approaches and hemithyroidectomy from the traditional approach, in particular, on the development of complications in the postoperative period, we can conclude that the proposed method of operation is not inferior to traditional technique, as well as other options for endoscopic interventions described in the literature [14-19].

Besides, the developed original method of three-trocar endoscopic gas extracervical hemithyroidectomy from axillary and thoracic approaches has a number of advantages over the previously described interventions. First, this method provides a better view of the operative field due to the fact that the third point, marked with a marker, is not fixed and can vary depending on the patient physique. Second, such arrangement of trocars eliminates the 'conflict of instruments' in the operative field: due to the preliminary insufflation of carbon dioxide, using the Veress needle, pneumatic preparation is provided, which facilitates the introduction of the endoscope.

Correspondence of the size of skin incisions to the diameter of trocars ensures the tightness of the operative 
cavity, which facilitates constant visual control during the surgery. Gas pressure of $18 \mathrm{mmHg}$, in contrast to previously proposed 6-8 $\mathrm{mmHg}$, provides an increase in the operative cavity volume and, accordingly, improves visualization. The creation of a primary cavity, which subsequently expands, turning into an operative cavity, improves the conditions for the introduction of instrumental trocars and makes this stage of surgical intervention safe. Additionally, using trocars 25 $\mathrm{cm}$ long allows reducing the diameter of the subcutaneous tunnels, the risk of injury to the subcutaneous vessels, and incidence of hematomas. The latter also reduces trauma and increases safety of the proposed operation.

\section{Conclusion}

In the course of our research project, a new method for three-trocar endoscopic gas extracervical hemithyroidectomy from axillary and transthoracic approaches was developed and implemented. The method is safe, because in terms of the number of postoperative complications, it is not inferior to traditional and other options for interventions on the thyroid. In addition, when using this operative technique, better visualization is provided during the entire operation. Another definite advantage of the proposed surgical variant is a highly aesthetic result. The use of a $25 \mathrm{~cm}$ trocar when performing endoscopic interventions from distant approaches may reduce the trauma of these operations, as well as increase their safety.

\section{Conflict of interest}

The authors declare no conflict of interest.

\section{References}

1. Maystrenko NA. Minimally invasive surgery of a thyroid gland. International Research Journal 2017; 55 (1): 144-51. (In Russian). https://doi.org/10.23670/IRJ.2017.55.165

2. Tan CTK, Cheah WK, Delbridge L. "Scarless" (in the neck) endoscopic thyroidectomy (SET): An evidence-based review of published techniques. World Journal of Surgery 2008; 32 (7): 1349-57.

3. Chand G, Agarwal A. Endoscopic thyroid surgery through breast and axillary approach. World Journal of Endocrine Surgery 2013; 5 (3): 85-8.

4. Park YL, Han WK, Bae WG. 100 cases of endoscopic thyroidectomy: Breast approach. Surgical Laparoscopy, Endoscopy \& Percutaneous Techniques 2003; 13 (1): 20-5. https://doi.org/10.1097/00129689-200302000-00005

5. Choe JH, Kim SW, Chung K-W, et al. Endoscopic thyroidectomy using a new bilateral axillo-breast approach. World Journal of Surgery 2007; 31 (3): 601-6. https://doi.org/10.1007/s00268006-0481-y

6. Shimazu K, Shiba E,Tamaki Y, et al. approach. Surgical Laparoscopy Endoscopy \& Percutaneous Techniques 2003; 13 (3): 196-201. https://doi.org/10.1097/00129689-20030600000011

7. Ohgami M, Ishii S, Arisawa $\mathrm{Y}$, et al. Scarless endoscopic thyroidectomy: breast approach for better cosmesis. Surgical Laparoscopy Endoscopy 2000; 10 : 1-4. https://pubmed.ncbi.nlm.nih.gov/10872517/

8. Ikeda Y, Takami H, Niimi M, et al. Endoscopic thyroidectomy by the axillary approach. Surg Endosc 2001; 15: 1362-64. https://doi.org/10.1007/s004640080139
9. Lee KE, Kim HY, Park WS, et al. Postauricular and Axillary Approach Endoscopic Neck Surgery: A New Technique. World $J$ Surg 2009; 33: 767. https://doi.org/10.1007/s00268-0099922-8

10. Emelianov SI, Kurganov IA, Kolesnikov MV, et al. Axillaryretroauricular endoscopic approach for thyroid operations. Endoscopic Surgery 2013; 2: 42-7. (In Russian).

11. Beltsevich DG, et al. Clinical guidelines of Russian Endocrinology Association on diagnosing and treatment of (multi)nodular goiter in 2015. Endocrine Surgery 2016; 10 (1): 5-12. (in Russian).

12. Semkina GV, Abrosimov AYu, Abdulhabirova FM, Vanushko VE. Assessment of results of repeated FNAB in patients with a nodular colloid goiter (analysis of original data and review of literature). Clinical and Experimental Thyroidology 2014; 10 (2): 32-7. (in Russian)

13. Vertyankin SV, Turlykova IA, Meshcheryakov VL, et al. Trocar for endoscopic surgery of thyroid gland: Pat. 185840 Russian Federation, IPC A61B 17/34/ №2018105997; 2018; 35: 7. (in Russian).

14. Vertyankin SV, Meshcheryakov VL, Cholakhyan AV, et al. Features of endoscopic interventions in conditions of thyroid diseases. In: Innovative technologies in endocrinology: Proceedings of the III Russian National Endocrinological Congress with international participation, 2017: 335-6. (in Russian).

15. Makaryin VA, et al. Intraoperative neuromonitoring during surgical interventions on thyroid and parathyroid glands: Indications and performance technique. Endocrine Surgery 2016; 10 (2): 5-16. (in Russian).

16. Kukhtenko YuV, Shulutko AM, Semikov VI, et al. Structure of thyroid gland diseases in patients of different age groups. Bulletin of Volgograd State Medical University 2016; (3): 59. (in Russian).

17. Choi JY, Lee KE, Chung KW, et al. Endoscopic thyroidectomy via bilateral axillo-breast approach (BABA): Review of 512 cases in a single institute. Surgical Endoscopy 2012; (26): 948. https://doi.org/10.1007/s00464-011-1973-X

18. Tan Z, Gu J, Han QB, et al. Comparison of conventional open thyroidectomy and endoscopic thyroidectomy via breast approach for papillary thyroid carcinoma. International Journal of Endocrinology 2015; 5. https://doi.org/10.1155/2015/239610

19. Choe JH, Kim SW, Chung KW, et al. Endoscopic thyroidectomy using a new bilateral axillo-breast approach. World Journal of Surgery 2007; (31): 601. https://doi.org/10.1007/s00268-0060481-y

\section{Authors:}

Sergey V. Vertyankin - DSc, Associate Professor, Chair of the Department of Surgery and Oncology, Saratov State Medical University, Saratov, Russia;

Isabella A. Turlykova - Instructor, Department of Surgery and Oncology, Saratov State Medical University, Saratov, Russia;

Vitaly L. Meshcheryakov - PhD, Assistant Professor, Department of Surgery and Oncology, Saratov State Medical University, Saratov, Russia;

Vladimir V. Grekov - Instructor, Department of Surgery and Oncology, Saratov State Medical University, Saratov, Russia;

Nikolay V. Chupakhin - PhD, Assistant Professor, Department of Surgery and Oncology, Saratov State Medical University, Saratov, Russia;

Yana E. Vanzha - graduate student, Department of Surgery and Oncology, Saratov State Medical University, Saratov, Russia;

Victoria A. Ivanova - student, School of Pediatrics, Saratov State Medical University, Saratov, Russia;

Kirill I. Zhurkin - undergraduate student, School of General Medicine, Saratov State Medical University, Saratov, Russia. 